Some thinkers, however, find such a view inadequate to account for the facts, and therefore postulate in addition some, to us unknown, purpose in the universe. Our developing knowledge of other peoples has replaced many illusions as to natural differences by the recognition of likenesses as well, and confirms the importance of the social environment. It is not unlikely that man's mental and moral development depends in part upon the relation between his inheritance and the physical and social environment in which he grows up. Dr. Myers analyses several modern environmental conditions and concludes that changes have occurred which justify a belief in human improvability; these improvements do not, however, appear to come from the innate improvability of a race but from the improvement in the social heritage. The paper is provocative and stimulating, and in view of Dr. Myers's intimate knowledge of many aspects of modern civilisation, it is worthy of very serious consideration. It is all the more important at the present time, when so much pessimism is shown in the interpretation of the changes which our environment is experiencing.

\section{British Poisonous and Edible Plants}

ExcEPTING works on poisonous plants from the agricultural and medical points of view, there is very little printed information available to the lay reader. Fortunately, most British poisonous plants are rare; but the most dangerous are those with an attractive and luscious appearance. Perhaps that is why, despite their scarcity, such plants are the cause of illness and even death to unwary ramblers, campers, and school children every year. The pamphlet recently published as a reprint from School Nature Study therefore comes as a timely warning, not only to the country child and the town child in the country, for whom it is written, but also to adults who take an active part in country life. The pamphlet," British Poisonous and Edible Plants", written by Miss Hilda F. Rendle, after a few introductory remarks, gives a list of edible plants found growing wild. These are divided into black fruits, scarlet fruits, seeds and nuts, flowers, leaves, roots, and fungi. The second part deals with the poisonous plants, giving not only the well-known plants such as laurel, bryony, deadly nightshade, etc., but also some of the less familiar types such as the spindle with its attractive pink fruit and orange seeds, potato 'apples', and acorns. A few of these are illustrated. It is a pity that the fungi were not given more space. Only the common mushroom (Psallista) is described, with the concluding remark that "all other fungi should be avoided". In the present day of extended country activities, this pamphlet should be welcomed by all school teachers, boy scouts troops, country rambling organisations, etc. Copies at $2 \frac{1}{2} d$. each or two shillings per dozen can be obtained from Mr. E. G. Clarke, 7 Stanley Avenue, Wembley, Middlesex.

\section{Acquisitions at the Natural History Museum}

The Department of Botany, British Museum, has received 320 plants collected by Mr. H. St. J. B. Philby, on his recent Arabian journey and presented by the King of Hejaz and Najd. The plants are of interest botanically as being from an area previously unexplored. It has to be remembered that, from an economic point of view, plants are of the greatest importance in deserts, and according to Mr. Philby the Arabs know them so well as camel food or otherwise that they are able to judge the date of the last rains from their presence or absence. The Arab name is attached to each plant. Acquisitions of the Department of Minerals include meteorites collected by Mr. Philby, a piece from the 15-ton mass of meteoric iron discovered in 1930 near Mbosi in Tanganyika Territory, a piece of a meteoric stone which fell recently near Kirkuk, Iraq, and a specimen of pitchblende from the recently discovered occurrence on the Great Bear Lake, North-West Territory, Canada. Dr. Robert Broom has presented to the Geological Department a small series of South African fossil reptiles, several of which are the types of genera and species recently established by the donor. They belong principally to Therocephalian and Dicynodont genera, and range from Permian to Trias in age. Through the generosity of Rear-Admiral H. Lynes, Mr. Jack Vincent has been collecting for the Museum in Portuguese East Africa, the birds of which are very little known; already two consignments have been received. A collection of more than a thousand birds from Yunnan obtained by the late Mr. G. Forrest, the well-known plant collector, has been presented by the Godman Exploration Fund, while Dr. P. A. Buxton has presented a collection of some 750 birds made by him during the War in Iraq and Persia.

\section{Publications of the Institut Henri Poincaré}

THE completed first volume of the Annales de l'Institut Henri Poincaré (Paris: Institut Henri Poincaré ; Les Presses Universitaires de France) contains a highly interesting set of papers on theoretical physics and its mathematical borderland, of varying degrees of difficulty, several of which have been referred to in our columns on their appearance. The contributions verging on the purely mathematical include two on integral equations, by Kostitzin and Carleman, one by Brillouin, on a hyperbolic equation, and two, by Lévy and Polya, on the calculus of probabilities. Relativity is represented by Einstein and de Donder, and quantum theory by Darwin, Fermi, Born, and Dirac. The other papers are by Brillouin, on fusion, and by L. Bloch, on band spectra. It will be evident that the list of authors is one of unusual authority, a feature continued in the first numbers of the second volume by the inclusion of Sommerfeld and Cabrera. Their respective papers also give in short the aim of all, which appears to be to comment on current problems, or to collect and criticise otherwise scattered work. The papers are based on lectures delivered under the auspices of the Institut Henri Poincaré, and the only important change to be desired is that less time should be allowed to elapse between the delivery of the lecture and the time when it appears in print.

\section{Population of England and Wales}

The "Text" (final) volume of the RegistrarGeneral's Statistical Review, England and Wales, 1930, has been published (H.M. Stationery Office, $2 s .6 d$. 
net). It contains the official commentary on the vital statistics contained in Parts i. and ii., Medical and Civil Tables, already issued. The population at the middle of the year was estimated at $39,806,000$ persons, made up of $19,075,000$ males and $20,731,000$ females, the excess of females being most marked in the age groups between thirty and fifty-five years. The death-rate, 11.4 per 1000 population, is the lowest on record. The deaths ascribed to cancer $(57,883)$ are the highest yet recorded, but when standardised are almost the same as, and no higher than, the preceding year. Attention is directed to the increasing mortality associated with motor-vehicles, and particularly with motor-cycles. During the six years 1925-30, motorcycles were associated with the deaths of 2752 young men between the ages of fifteen and thirty-five years, which is 2.8 times the number killed in the preceding 14 years. The corresponding numbers of young women were 316 and 79 , a fourfold increase.

\section{Grant in Aid of African Research}

A FURTher grant in aid of research in Africa by the trustees of the Rockefeller Foundation is announced. The sum of $£ 3000$ per annum for a period of three years has been granted to the School of Oriental Studies in the University of London for the furtherance of research in African linguistics. This subject is already included in the curriculum of the school as part of the work of the Department of Phonetics and Linguistics, acting in co-operation with the International Institute of African Languages and Cultures. Now that the Oriental Institute has this additional fund at its disposal, it will be possible to extend its activities in this subject especially in the field of original research. It will be remembered that the Rockefeller Foundation is already assisting liberally African research in Great Britain by the grant of $£ 5000$ a year, to be increased in certain contingencies to $£ 10,000$, to the International Institute of African Linguistics and Cultures ; and this grant is being used to meet the cost of a scheme of research which has been planned to cover a period of five years.

\section{Announcements}

Sir William Braga, director of the Royal Institution, left England on June 25 for a lecture tour in South America under the auspices of the IberoAmerican Institute of Great Britain, of which H.H. the Prince of Wales is president. On the previous day Sir William was received by His Highness, who expressed his interest in the tour. Sir William is due at Buenos Ayres on July 15 and leaves there on Aug. 1, when he goes on to Rio de Janeiro, arriving there on Aug. 6 and staying until Aug. 14. At both places he will be the guest of the British Ambassador and will deliver lectures on recent work on X-rays and crystal analysis. Sir William is expected back in England about Aug. 29.

As noted briefly in our issue of June 11, p. 860 , the centenary of the birth of Sir William Crookes fell on June 17. In 1859 he founded the Chemical News, and the issue of that journal for June 17 is very appropriately dedicated to his memory. Lord Rutherford contributes a descriptive article on the artificial transmutation of elements, Sir Harry McGowan has a short article on Crookes's well-known forecast of a world wheat shortage in relation to chemical industry, and other articles deal with various aspects of Crookes's life and scientific work. The issue includes full-page reproductions of photographs of Crookes and Lord Rutherford.

The Medical Research Council announces that, on behalf of the Rockefeller Foundation, it has made the following awards of travelling fellowships for the academic year 1932-33; these fellowships are awarded to graduates who have had some training in research work either in the primary sciences of medicine or in clinical medicine or surgery, and who are likely to profit by a period of work at a chosen centre in America or, in special cases, in Europe, before taking up positions for higher teaching or research in the British Isles :--Mr. C. P. Beattie, Bacteriology Department, University of Edinburgh ; Mr. W.D. W. Brooks, St. Mary's Hospital, London; Dr. Eleanor M. Creak, Maudsley Hospital, London; Mr. I. G. W. Hill, Royal Infirmary, Edinburgh ; Mr. W. A. Mackey, Department of Surgery, University of Glasgow; Mr. D. J. Macmyn, King's College Hospital, London; Dr. J. C. Moir, University College Hospital, London. In view of the high qualifications of so many of the candidates, the Council greatly regrets that it has not been possible to make a larger number of awards.

Messrs. H. K. Lewis and Co., Ltd., 136 Gower Street, W.C.1, have just issued a very useful classified catalogue of books, in new condition, on physics and mathematics. An admirable feature is the insertion of the year of publication of each volume.

UPWARDS of 2000 works dealing with ornithology are offered for sale, at what appear to be reasonable prices, by Messrs. Wheldon and Wesley, Ltd., 2 Arthur Street, W.C.2, in catalogue New Series, No. 28. The catalogue is obtainable free upon application.

Applicatrons are invited for the following appoint ments, on or before the dates mentioned :-A fulltime lecturer in the Department of Building of the Leedis Technical College - The Director of Education, Education Department, Calverley Street, Leeds (July 6). A teacher of metalwork and technical drawing, and an assistant master to teach principally chemistry and mathematics, in the Junior Technical School of the Castleford, Normanton, and District Mining and Technical Institute, Whitwood-M. G. Swaine, Education Offices, Castleford (July 8). An assistant lecturer in mathematics in the University of Birmingham-The Secretary, The University, Birmingham (July 15). A lecturer in pharmacology in the Department of Physiology of the University of Bristol-The Secretary and Registrar, The University, Bristol (July 22). A secretary of the Jamaica Agricultural Society-The Secretary, Jamaica Agricultural Society, 11 North Parade, Kingston, Jamaica, B.W.I. (Sept. 5).

$$
\text { No. } 3270 \text {, Vou. 130] }
$$

